Bol. Acad. peru. leng. 47. 2009 (111-124)

\title{
CERVANTES EN EL PERÚ *
}

\author{
Carlos Eduardo Zavaleta \\ Academia Peruana de la Lengua
}

\section{Señores:}

Agradezco a nuestra Academia Peruana el permitirme hablar ante ustedes, en una fecha esencial y memorable, en que se cumplen 402 años de la muerte del insigne Miguel de Cervantes Saavedra, cuyo nombre ya es ciertamente inmortal, qué duda cabe.

La sabia costumbre de reunirnos en esta fecha fue iniciada en el Perú, el 23 de abril de 1934, por el entonces Director de la Academia, don José de la Riva-Agüero, ilustre erudito, historiador y crítico a la vez, quien empezó su discurso así: "Miguel de Cervantes, por los maravillosos privilegios del genio, representa para los dispersos pueblos hispánicos, lo que Homero para los griegos, lo que son Shakespeare para los anglosajones y Dante para los italianos, el seguro de indestructible hermandad, la inmaculada bandera de la unidad espiritual perdurable. El Perú, que ha sido y es, en América del Sur, país tan tradicional (e imborrablemente español) no puede

Discurso pronunciado el 21 de abril de 2008, en el ciclo de conferencias organizado por la Academia Peruana de la Lengua, en el Instituto Peruano Norteamericano. Como se sabe, el Día del Idioma se celebra los días 23 de abril de cada año, pero se cambió la fecha para no coincidir con la convocatoria al Congreso Internacional de Lexicología y Lexicografía. 
aún, menos que los otros hispanoamericanos, faltar en esta solemnidad conmemorativa, de imponderable trascendencia". 1

Esta buena costumbre fue cumplida y acentuada en la década de los años 40s. A propósito, yo recuerdo de modo vívido la celebración de un ciclo de conferencias convocadas por el Rectorado de San Marcos, en 1947, conmemorando el 4to. centenario del nacimiento de Cervantes, de las cuales me impresionaron dos, las de Luis Alberto Sánchez y José Jiménez Borja, que citaré en detalle más adelante.

Dicho esto, organicemos nuestro, tema y tracemos en la mente el largo viaje de Cervantes en nuestro país, a través de ensayos y discursos, incluyendo homenajes singulares, digo, cuentos, novelas o poemas dedicados ya sea al Maestro o a algunos de sus personajes.

¿Quién inicia el desfile de estas aproximaciones? Pues don Pedro José Rada y Gamio (1873-1938), quien pronunció un discurso sobre el Quijote, el 24 de julio de 1891, ante los miembros del Club Literario de Arequipa, con un lenguaje ampuloso, de cortesías, casticismos y modales, todo un elogio al autor y a su gran libro, pero también dio consejos como éste, por ejemplo: "Comprendéis muy bien lo que significan las letras, y por eso siempre debéis tener presente El Quijote para cultivar la sátira, sin arrojar veneno; para pintar al hombre sin degradarlo; para censurar sus defectos, sin clavarle el puñal del desprecio; para hacer reír el rostro, sin hacer llorar el alma".

¡Vaya locuaz cervantino y arequipeño! Rada y Gamio fue docente en la Universidad de San Agustín, bachiller en letras, abogado y doctor en ciencias políticas y administrativas, grado que ganó ya en San Marcos; y luego, encargado de negocios ante la Santa Sede, diputado por Arequipa, Alcalde de Lima, numerosas veces ministro de Estado y fiel partidario del ex Presidente Leguía, por lo cual también fue prisionero en San Lorenzo

José de la Riva-Agüero, "Cervantes", en Obras Completas, III, p.6.

Pedro José Rada, “El Quijote”. Folleto. Arequipa, Imprenta El Deber, 1891, reproducido en el volumen inédito Cervantes en el Perú, por C.E.Z., pp. 1-5. 
y desterrado en Arica, pero asimismo supo escribir ensayos sobre el Arzobispo Goyeneche, Mariano Melgar, y la historia de Arequipa, además de estudiar a Santa Teresa de Ávila y Santa Rosa de Lima. Según el historiador Alberto Tauro, llamó la atención de su época y fue celebrado por sus discursos hiperbólicos en alabanza del ex Presidente Leguía. Cumplimos con decir que al momento de pronunciar su discurso de elogio al Quijote, él sólo era un flamante bachiller en Filosofía y Letras.

Los numerosos autores que le siguen en su apego a Cervantes deben ser divididos en tres grupos, a fin de atenderlos mejor. El primero lo conforman renombrados eruditos, mayormente historiadores, bibliógrafos y críticos literarios a la vez, encabezados por Ricardo Palma, y más tarde, a partir de la década de los años 20s, por José Jiménez Borja, José de la Riva Agüero, Luis Alberto Sánchez, Raúl Porras Barrenechea y Aurelio Miró Quesada Sosa. Es un grupo impresionante, que podemos llamar fundador de los estudios cervantinos en el Perú.

El ensayo, o crónica, o tradición, de Ricardo Palma se titula lacónicamente "Sobre el Quijote en América" y es mayormente bibliográfico, dedicado a seguir la suerte de los primeros ejemplares llegados al país desde el mismo año de 1605, fecha de impresión de la primera parte del libro. El texto se incluyó en el tomo de Mis últimas tradiciones peruanas, Barcelona, 1906. ${ }^{3}$ Por entonces no existía siquiera una edición peruana del Quijote, pero sí ya se habían publicado las ediciones mexicana y argentina, lo cual sin duda incomodó al tradicionista. Tampoco se conocían artículos o ensayos notables, ni menos obras inspiradas directa o indirectamente por los personajes cervantinos, como sí se habían reflejado en los admirables Capitulos que se le olvidaron a Cervantes (1870), del ecuatoriano Juan Montalvo, (1832-1889), y en la novela Quijotita, del mexicano Fernández de Lizardi.

Quizá lo más importante de esta pesquisa de Palma sean dos hechos, que un amigo español de Cervantes, don Juan de Avendaño, empleado de las Cajas Reales de Lima y Trujillo, recibió aquí, en Lima, un ejemplar

3 Ricardo Palma, "Sobre El Quijote en América", texto tomado de Mis últimas tradiciones peruanas. Barcelona, 1906.

Bol. Acad. peru. leng. 47(47), 2009 
dedicado del Quijote; y segundo, que uno de los seis ejemplares que Palma menciona llegó a manos de Fray Diego de Ojeda, el admirado autor de la Cristiada. Por otro lado, citando asimismo este ensayo, el historiador Porras Barrenechea añade que el estudioso español Rodríguez Marín, consigna el hecho de que en 1607 (dos años después de la aparición del Quijote), al anunciarse en el Perú la llegada del Virrey Marqués de Montesclaros, hubo en Pausa, capital del corregimiento de Parinacochas, una fiesta de cañas y sortijas, en que salieron efigies del caballero don Quijote y de su escudero Sancho, quien inclusive echó algunas coplas....

Tras de Palma, por orden cronológico, se alinea el renombrado erudito, don José Jiménez Borja, eximio docente de San Marcos y de la Católica, y después Director de la Academia. Su ensayo "Descifración del Quijote" ${ }_{4}^{4}$ de 1933, un año antes del discurso de Riva-Agüero, es un texto ejemplar, admirable, pues siendo él un crítico peruano, entra con soltura y sabiduría en el campo español, y hace un espléndido resumen de sucesivos juicios de críticos y filósofos españoles, dichos hasta los años 30 sobre el Quijote. Es decir, un tema propiamente universal tratado de punta a cabo. Y no es una sorpresa que haya sido así, pues ya en 1927 había presentado en San Marcos una luminosa tesis doctoral, titulada Elogio de Don Luis de Góngora, ${ }^{5}$ tema harto difícil y exquisito, sobre el que se dedicaría sólo en 1961 el famoso crítico español Dámaso Alonso, con el ensayo Góngora y el Polifemo.

En 1935, en su segundo discurso sobre temas cervantinos, don José de la Riva-Agüero se ocupa de La Galatea, ${ }^{6}$ primera novela de Cervantes, y obra, según dice Riva-Agüero, conocida y leída en Lima por sus encantos descriptivos, ensoñadores y nostálgicos, y por el eco de tres países que amaba Cervantes, España, Italia y Portugal, dentro del marco de ejemplos

$4 \quad$ José Jiménez Borja, "Descifración de 'El Quijote”, reproducido de su original de 1933, en José Jiménez Borja. Crítico y maestro de la lengua. Lima, Fondo Edit. UNMSM, pp. $115-124$. en la Facultad de Letras de la UNMSM, 1927, publicada en la revista Letras, Lima, UNMSM, 1929.

6 José de la Riva-Agüero, "La Galatea", en Obras completas, III, pp. 19-44. 
que daban Boccaccio y la Arcadia de Sannazaro, afirmando desde el comienzo que esta novela es poética. Si en su primer discurso titulado escuetamente "Cervantes", Riva-Agüero había mezclado sus recuerdos personales de Madrid y Alcalá de Henares, y luego los vínculos generales, sobre todo poéticos, biográficos e históricos entre la obra cervantina y el Perú, e incluso entre nuestros dos países, y todo a propósito del ejemplo del Quijote en el arte y en la vida, aquí, en su nuevo discurso como Director de la Academia, se dedica más específicamente a La Galatea, la primera novela de Cervantes, y luciendo amplia información y exponiendo sus propios juicios histórico-literarios.

Continuemos la pesquisa. En 1948 vuelve a sorprendernos la sutileza y trabajosa labor crítica de nuestro José Jiménez Borja, esta vez sobre la obra más difícil y menos estudiada de Cervantes, el Persiles y Sigismunda, en su ensayo titulado precisamente "Primor y esencia del Persiles". Pocas veces un crítico nacional habrá estudiado una obra con mayor competencia y soltura; inclusive el estilo del crítico parece beneficiarse con la calidad y sutileza de lo que lee. Según Jiménez Borja, el libro aparecido un año después de la muerte de Cervantes constituye un documento patético de los últimos días del autor.

Cito: "El esfuerzo de redactarlo y de pulirlo fue paralelo con el debilitamiento físico y la enfermedad del anciano. Las páginas finales, abreviadas y casi truncas, parecen sufrir el golpe acezante de la agonía"? En verdad, es una lástima que grandes autores como Lope, Gracián y Suárez de Figueroa fulminaran los libros de Cervantes con el peso de su incomprensión y sus burlas. Por eso, quizá el mismo Cervantes dijo que el Persiles "ha de ser o el más malo o el mejor que en nuestra lengua se haya compuesto, quiero decir de los de entretenimiento; y digo que me arrepiento de haber dicho el más malo porque según la opinión de mis amigos ha de llegar al extremo de bondad posible". En el fondo, pues, confiaba mucho en esta novela considerada bizantina, de las muchas variantes que había en su época, "caracterizada por la rapidez

7 José Jiménez Borja, "Primor y esencia del Persile", en Varios, 4to. Centenario de Cervantes. Lima, UNMSM, III, pp. 79-99.

Bol. Acad. peru. leng. 47(47), 2009 
y copiosidad de la acción, por el misterio y la sorpresa, por la sucesión portentosa de náufragos, incendios y otras catástrofes análogas, así como de matrimonios, muertes y nacimiento inesperados, en un ambiente de geografía y sociedad variables al infinito, que sólo se podría comparar con la audacia del cinedrama moderno", aun cuando, sin embargo, la crítica haya señalado influencias precisas de autores lejanos a nosotros como Heliodoro (Teógenes y Cariclea) y Aquiles Tacio (Clitofonte y Leucipe).

Quien sigue ahora en esta cronología de eruditos, es Raúl Porras Barrenechea, quien publicó dos ensayos importantes, "Cervantes en el Perú" (1943) y "Cervantes, la Camacha y Montilla" (1950). ${ }^{8}$ El primero es un ejemplo de investigación que, de fuentes peruanas, pasa a las españolas, para envolverlas en un solo motivo, un hecho real y simbólico que las conecta. ¿Cuál sería éste? Luego de un corto preámbulo, dispara pronto su tema, osado y sutil a la vez, el origen quizá peruano, o ciertamente peruano después, de la carta de Sancho a su mujer (glosada en el capítulo XXXVI de la segunda parte del Quijote), cuyo modelo sería una carta verdadera, conocida en un proceso judicial auténtico, seguido al ex Gobernador del Perú, Vaca de Castro, fechada en el Cuzco, el 28 de noviembre de 1542, cinco años antes del nacimiento de Cervantes, y que fue un documento público e inclusive comentado en rumores y burlas en la ciudad de Valladolid. En el texto del Quijote, la Condesa pregunta a Sancho si él escribió la carta a su mujer Teresa, y aquél responde: "Ni por pienso, porque yo no sé leer ni escribir, puesto que sé firmar", frase memorable que quizá podría evocar, según Porras, al mismísimo Francisco Pizarro. Si bien el ensayo se titula "Cervantes en el Perú", muy bien podría titularse "El Perú en Cervantes”. ¡A tanto apunta la investigación de Porras!

Su segundo ensayo, "Cervantes, la Camacha y Montilla" (1950), tiene el mismo aire brillante y aun osado, pues Porras esclarece la estancia poco estudiada de Cervantes en Montilla, donde habría recogido la imagen popular de una hechicera, la Camacha, que figuraría luego en

8 Raúl Porras Barrenechea, "Cervantes en el Perú”, en La Prensa, Lima, 23 abril 1943; y "Cervantes, la Camacha y Montilla", en revista Mar del Sur. Lima, setiembrenoviembre 1950, pp. 55-64. 
la novela ejemplar "El coloquio de los perros", y Porras lleva al máximo su investigación al publicar inclusive el testamento, de 1569, que dejó la mujer verdadera, la cual habría inspirado al personaje ficticio y pícaro.

Este grupo de encomiables eruditos, mayormente historiadores, culmina con don Aurelio Miró Quesada Sosa, cuya diligente serie de estudios sobre las grandes figuras del Siglo de Oro (Lope, Calderón, Quevedo), engloba también a Cervantes el poeta (en "El Canto de Calíope", de La Galatea) y sus lazos con personajes peruanos, como don Juan Dávalos de Ribera, no sólo conocido por haberse alistado contra el pirata Drake, sino por su figuración en la propia corte española. Además, como director de la revista Mar del Sur, Miró Quesada fue un propulsor de estudios literarios clásicos y modernos, y finalmente, en 1992, concretó su largo proyecto de publicar una edición peruana del Quijote, ilustrada por el reconocido pintor Fernando de Szyszlo.

El segundo grupo de estudiosos está formado por médicos humanistas, a cuya cabeza se halla don Honorio Delgado y su admirable ensayo "La locura del Quijote”, publicado, mucha atención a la fecha, en 1916, cuando el joven galeno apenas tenía 24 años, lo cual duplica su valor. El psiquiatra y psicólogo Honorio Delgado fija muy alto su tarea: estudiar aquello que, en el arte, "sobrepasa los límites de la verdad vulgar, dando magnitudes hiperbólicas a determinados rasgos, subordinando los demás a la armonía y unidad artística": he ahí, según él, el procedimiento de la inspiración genial de realizar su propia encarnación. "Así, el visionario Quijote, por su paranoia expansiva ha inmortalizado a su biógrafo... a expensas de la grandeza de su patria, matando... con el ridículo la suprema virtud de la hispana estirpe". ${ }^{9}$ Luego señala una "canalización obstinada" de la actividad mental y corporal, en el sentido de la inclinación dominante (práctica de los ideales caballerescos); pero de este esquema psicopático inicial, Delgado descubre una paranoia (unilateralización pertinaz en la esfera de las concepciones y del juicio) y busca una etiqueta para la

$9 \quad$ Honorio Delgado, "La locura del Quijote", originalmente publicado en la revista La reforma médica. Año II, N. ${ }^{\circ}$ 19, Lima, febrero 1916, y reproducido en Acta Herediana. Vol. 36, Lima, octubre 2004-marzo 2005.

Bol. Acad. peru. leng. 47(47), 2009 
vesania (o demencia) de nuestro personaje, sujeta ya a los nuevos estudios de comienzos del siglo XX. Y así califica a don Quijote como "idealista apasionado, pero no puro", pues el personaje presenta asimismo ideas de persecución, desdoblamiento de personalidad, con un estado onírico recurrente, o viviendo en un estado crepuscular de la conciencia (por ejemplo, añado yo, en el pasaje de la cueva de Montesinos), por entre sucesos fantasmagóricos, pero sin olvidar las frases melancólicas de la así llamada Triste Figura. Y todo ello, subraya Honorio Delgado, para llegar a lo más inverosímil, al retorno a la cordura, o sea la desaparición de Alonso Quijano en beneficio de la "normalidad", privando al gran loco Quijote de morir en su ley (al incumplir esa función esencial de la vida). Pero entonces, nos dice el eminente médico, surge una pregunta mayúscula, "ifue el Quijote la verdadera historia de la locura de Alonso Quijano, o todo lo que fabula es creación fantástica, sublime?”.

Luego de este análisis psiquiátrico, hay un silencio científico de casi treinta años en la bibliografía peruana.

El segundo médico y psiquiatra que se atreve con el tema es Carlos Gutiérrez Noriega (1906-1950), a quien debiéramos conocer mucho más en la cultura peruana, pues él abarcó temas muy variados, la antigüedad prehispánica, las especialidades farmacéuticas, y dos plausibles trabajos sobre la obra cervantina: "Contribución de Cervantes a la psicología y psiquiatría" (1944), fíjense qué titulo, reconociendo al autor del Quijote un conocimiento científico y vasto de la mente humana, que muchos le han negado; y su segundo ensayo es un nuevo remate en profundidad. Se titula "Significado y trascendencia del humorismo en Cervantes", ${ }^{10}$ publicado en 1948, en la revista San Marcos, de gran circulación por entonces. El ensayo es la culminación del lugar que, según él, debe ocupar Cervantes en el pensamiento mundial. Estudia la obra cervantina con un caudal de referencias que abarcan la antigüedad griega, latina y aun la literatura

10 Carlos Gutiérrez Noriega, "Significado y trascendencia del humorismo en Cervantes", en revista San Marcos, N. ${ }^{\circ}$ 4, Lima, abril-mayo-junio 1948, pp. 43-69. El ensayo anterior, "Contribución de Cervantes a la psicología y psiquiatría" es citado por Luis Alberto Sánchez en su respectivo ensayo. 
oriental, china, con las cuales coteja la obra de Cervantes y su espíritu humorista, trascendentalista y enciclopédico. Señala las cualidades del humorista en sí, luego encaja el modelo en el curso de la literatura clásica (incluso la oriental), y de ahí pasa a revelar la personalidad de Cervantes y sus ideales modernos, para descubrir que el humorismo europeo se inicia en España.

Para él, los héroes antiguos, Ulises, Eneas y Dante, descienden al infierno en busca del enigma psicológico que está fuera del yo, pero el infierno al que desciende el Quijote sólo está en su propia mente. El hallazgo de tal verdad, según él, tiene un sentido muy humorístico. Luego, añade, hay humorismo también en el sentido eminentemente lúdico de todos los personajes y sucesos del libro.

Cito: "Hay casi un convenio entre los dos protagonistas para entregarse, engañándose a sí mismos, al juego de aventuras. Las competencias de don Quijote con supuestos 'enemigos' tienen un doble sentido, humorista y lúdico, pues hay inclusive en ambos un estricto aislamiento de todo lo que es serio y real en la vida humana; y hasta los mismos pensamientos están en el ámbito irreal del mundo lúdico. Inclusive los ideales son tomados de los libros de caballerías... Lo humorístico adquiere, entonces, la calidad de una doctrina integral y profunda". ${ }^{11}$

Lamento que por razones de tiempo, sólo voy a mencionar nombres de otros distinguidos médicos y psicólogos que se han dedicado a Cervantes, entre los cuales no olvido a Uriel García, Oswaldo Salaverry y Leopoldo Chiappo.

Y así, con estas abreviaturas, llegamos al gran caudal, al río principal de los críticos literarios propiamente dichos, que han enfocado sus miradas a una obra tan rica en matices como la de nuestro Maestro. El primero en surgir debe ser y lo es Luis Alberto Sánchez, quien en 1948 dictó una conferencia de veras amena y fecunda titulada "Preludio cervantino", ${ }^{12}$

\footnotetext{
$11 \quad$ Ibid, pp. 58-59.

12 Luis Alberto Sánchez, "Preludio cervantino", en 4to. Centenario de Cervantes, Lima, UNMSM, 1948, pp. 101-136.
} 
título que explica su calidad introductoria y quizá también la rapidez en citar tanto los sucesivos libros de Cervantes como los de peruanos tocados por la magia del Maestro, desde la época virreinal, hasta la emancipación y la república, citando, salteando, diré, sobre opiniones y frases de poetas y escritores, empezando por los del Canto de Calíope, y luego de Olavide, Palma, Pardo, Segura, Juan de Arona, Gutiérrez de Quintanilla, Chocano, Ventura García Calderón y Valdelomar. Pero en él lo principal no está en la relación de nombres, sino en los puentes, en las asociaciones de ideas, en el fluir de la propia prosa, tan cálida como la de Valdelomar o la belle époque, su mejor libro. En fin, el ensayo es una satisfecha voz de gratitud por la influencia de Cervantes en el quehacer literario del Perú y es el fruto de un aprovechado lector de literatura española.

Tras de Sánchez y del año 48 en adelante, y durante más de 50 años, prosiguen los estudios y elogios cervantinos, con las firmas de, por ejemplo, Luis Jaime Cisneros, Wáshington Delgado, Marco Martos y de nuestro gran novelista y crítico Mario Vargas Llosa, cuyo prólogo a la última edición académica del 2005 ha despertado tantos ecos. ${ }^{13}$

Merece una mención especial el año del 2005, en que, por fin, al unísono, las principales universidades e instituciones culturales del país organizaron coloquios, congresos, conferencias, charlas que se publicaron en revistas enteras dedicados al Maestro Cervantes. Yo he recogido una buena parte de esa producción, ahí están los plausibles trabajos de Carlos García Bedoya, Antonio González Montes, Edgardo Rivera Martínez, Fernando Rodríguez Mansilla, pero es difícil que los organizadores de coloquios cedan los privilegios de edición a un colega que publicará ésta su antología mañana o pasado mañana. Esa es la única razón de algunas ausencias, que espero resolver pronto.

13 Nos referimos a los ensayos "Escolio cervantino", por Luis Jaime Cisneros; "Cervantes el Quijote”, por Wáshington Delgado; “Poesía diseminada en el Quijote”, por Marco Martos; y "Una novela para el siglo XXI" (fragmento), por Mario Vargas Llosa, que asimismo se recogen en el libro inédito Cervantes en el Perú, antología, selección de textos y notas por C.E.Z. 
Y por lo demás, deseo agradecer la contribución de especialistas en otros campos, por ejemplo en la antropología, como son Luis Millones y Aníbal Quijano, a quienes he tenido en cuenta; y también a un escritor y traductor del chino tan profesional como Guillermo Dañino.

Finalmente, tampoco debo omitir a un pequeño grupo de creadores literarios, autores de cuentos, novelas, piezas teatrales y poemas dedicados a nuestro genio de la lengua. Así, por ejemplo, el primer cuentista del país, cronológicamente hablando, Carlos E. B. Ledgard, publicó en 1899, el libro de cuentos Ensueños, donde aparece el titulado "El Quijote", en un curioso ambiente universitario de Heildelberg, nada menos, en que un personaje latinoamericano defiende la honra de una muchacha y muere por su causa quijotesca. Luego, el novelista Ciro Alegría, no sólo reveló ser un buen lector del Maestro, sino que publicó un breve ensayo sobre la estructura del gran libro, y ése es justamente el titulado "Don Quijote, Sancho y un nexo maestro", donde afirma que fue un acierto espléndido el inventar a Sancho como co-protagonista. Juan Manuel Polar, un escritor arequipeño, publicó en 1925 la novela Don Quijote en Yanquilandia, rindiéndole un homenaje al Maestro y pintando el viaje de los famosos protagonistas a tierras sólo a medias inventadas, a Yanquilandia, a una modernidad más coetánea, y asimismo a los detalles costumbristas y aun folklóricos de su amada ciudad de Arequipa. Lo laudable aquí es la prosa adrede castiza y fluida, de largas frases y con ritmos y cierta musicalidad aprendida en la lectura cervantina, incluso trasladando personajes, episodios y aventuras parecidas a las del original.

Por otro lado, hay una pieza teatral del poeta y dramaturgo Juan Ríos, titulada "El Quijote" (1946), en seis cuadros, donde hay algo así como una reinterpretación del significado poético aun filosófico de la obra.

Respecto a poesías, aparte de las citadas por Sánchez, hay dos textos, uno de José María Eguren, poeta de magnitud digamos ya clásica, y otro de Jorge Eduardo Eielson, autor de la generación de los 50s, cuyos elogios veremos enseguida. He aquí el de Eguren:

"Desearía para escribir sobre Cervantes un aire antiguo lleno de gracia; desearía la agilidad de su vida, su mirada de su sombra y su pluma de águila. 
"Un apunte apenas le dedico, no me atrevería a un ensayo, pues el mejor acierto sería siempre minúsculo. Supo disipar la bruma que ciega la mirada y leyó en el corazón de los hombres la escritura ignota, la verdad de la vida: dio a sus personajes las palabras propias, expresiones inconfundibles, las que serían ajenas en otros labios. Trazó un símbolo inefable, el más excelso de los símbolos vivientes: el símbolo de espíritu. Su Quijote fue grande a cada prueba. La galantería y el valor, la nobleza del alma y el amor. Las virtudes poéticas supremas. Su cuerpo era agudo como las agujas góticas, su espíritu era un rayo. Sancho, redondo y material, es un tipo pintoresco comparable en lo exterior o en la forma expresiva a las figuras de los mejores cuentos de maravilla.

"Cervantes tenía el espíritu pintoresco del autor del "Sueño de una noche de verano", pero con una humanidad que solamente Shakespeare y Moliére han ofrecido. Cervantes, como el autor de Hamlet, supo adivinar al hombre futuro a través de los siglos. Cervantes fue un genio auténtico. Sus símbolos son más simples y primitivos que los de Shakespeare, pues éste pinta al hombre moderno: nos pinta con nuestro proceso interior de dudas y anhelos. Cervantes exterioriza al hombre en general, en el orden estético y lógico. Sus mujeres, gitanillas y graciosas, de mejillas templadas al fuego moreno y, los rojos de canela, son tipos encantadores. Sus rinconetes, sus pilluelos, son niños fáciles que se les creería murillescos. Cervantes no fue un imaginero. Su fantasía, que tuvo tanto del hombre, era sintética: sus descripciones son dinámicas; procede por arranques, como en Beethoven. Fue un incomparable lírico en la hondura del amor, del misterio de la vida". ${ }^{14}$

Gocemos ahora del poema vanguardista de Eielson:

14 José María Eguren, “Cervantes”, en La Prensa, Lima, 24 abril, 1943. 


\section{EN LA MANCHA}

\section{Sueño de Sancho}

Abril abajo pastan bueyes en canchas de fútbol floridas, desiertas. La bulla de cedros y eucaliptos a un costado, levántase en andas de frescura.

Árboles rosas cubren el panteón de al lado, en donde pían los difuntos provistos de un dorado pico.

Sancho allí dormido, entre la noche y el día, exhala un largo, violento y rojo ronquido, con tufo de sopa y vinosa memoria. A su estruendo salen los muertos aturdidos, como tras el diluvio lunas y planetas y ante el terremoto cráneos y sarcófagos al polvo.

O como a silbato del Juicio Final en la cancha de fútbol. Juegan los muertos ante él con arcaica pelota.

Sancho ruidoso, acostado, casi sembrando la tierna, bermeja mejilla, la poderosa barriga en tierra, se divierte, mientras rueda lamiendo las fuentes doradas de asado, ollas de nueces al brasero, pailas de hirvientes puchero, sonoros bollos, aceitunas y durazno en el césped.

Tras el otero ve Sancho, perderse el sol mientras los muertos se tornan violeta, se entristecen y dejan de jugar. Rayados por la tarde amarilla, verde y azul, aléjanse a sus nichos, macilentos, cargados de largos calzones y chompas en polvo. Sancho aburrido, bosteza, vuélvese en el césped nocturno y brillante: ¡bah! ${ }^{15}$

En fin, lo que también me ha estimulado al preparar esta mi antología Cervantes en el Perú, ha sido el pensar que estábamos haciendo lo que otros, españoles y latinoamericanos, estaban haciendo en sus países, como hemos podido comprobar ante los libros alusivos que nos llegaban a Lima. Por ejemplo, El Quijote visto desde América, antología de Jesús García Fernández (Madrid, Visor, 2005), donde el único peruano que aparece

15 Jorge Eduardo Eielson, "En la Mancha, Sueño de Sancho", en Poesía escrita, Lima, 1976.

Bol. Acad. peru. leng. 47(47), 2009 
es don Ricardo Palma, con su ensayo de 1906. Imagínense, ustedes, ¿y acaso después de 1906, no nos hemos interesado por lo que sucedía en el Perú? Asimismo, hay otros libros más específicos y exquisitos como el de La Generación del 27 visita a Don Quijote (Madrid, Visor, 2005), que es asimismo una selección de García Fernández, aunque haya también otros que son espléndidamente panorámicos, si bien no muy nuevos, como Gente de Cervantes. Historia humana del idioma español, por Juan Ramón Lodares (Madrid, Taurus, 2001).

En una palabra, en una frase final, estamos haciendo un visible esfuerzo para ponernos al día, y para invitar a los colegas de ambos continentes a que se pongan ellos también al día, sobre los diversos trabajos de escritores y eruditos peruanos.

Ojalá lo hagan. Muchísimas gracias. 